\title{
La infancia en debate: entre derechos y necesidades
}

\author{
Dr. Jorge Castro Morales"
}

\section{Introducción}

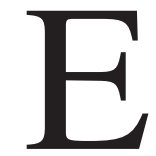

1 abordaje de la problemática de la infancia se debate entre los postulados de quienes apuntan a la consolidación de sus derechos a partir de los enunciados de la Convención Internacional de los Derechos del Niño, la legislación nacional de cada país sobre la materia y los dispositivos de vigilancia y cumplimiento del ejercicio de esos derechos, de un lado. Del otro está el enfoque pragmático de la satisfacción de sus necesidades, tomando en cuenta las emergencias del día a día.

La tentación maniquea de descalificar al discrepante, costumbre generalizada en el ámbito latinoamericano, podría llevarnos fácilmente al expediente de caracterizar la perspectiva de los derechos como el fútil ejercicio de judicialización de un hecho social; en tanto que la satisfacción de las necesidades no sería otra cosa que un asistencialismo reciclado.

Ambos enfoques tienen, qué duda cabe, ventajas y desventajas intrínsecas, así como resultados en su aplicación práctica que pueden ser concurrentes a sus propósitos, pero también paradójicamente contraproducentes. El autor, desde su experiencia clínica profesional y el trabajo de campo en comunidades andinas y con los niños y adolescentes trabajadores, a contrapelo de los postulados en boga, favorece la perspectiva de las necesidades y lo hace por razones que espera queden suficientemente explícitas en este artículo. El lector podrá, desde ya, asumir que

* Presidente de la Sociedad Peruana de Psiquiatría de Niños y Adolescentes. Profesor de la Maestría en Políticas Sociales de Infancia de la Universidad Nacional Mayor de San Marcos, Lima. 
su empeño está sesgado por una óptica excluyente. Pero también podrá, si lo desea, emprender un detenido análisis de este debate en el que no puede haber, como lo señalara Kuhn ${ }^{1}$ a propósito de la construcción de los paradigmas, objetividad absoluta o percepciones carentes de carga afectiva.

El corolario de esta aventura intelectual (que tiene interconexiones corticales afectivas, como lo pusiera en evidencia Le Doux y popularizara Goleman²), debería conducirnos a la conclusión que la única forma de hacer efectiva una advocacy acorde con las demandas de los propios niños y adolescentes, es el ejercicio de su participación auténtica en todas las decisiones que conciernan a su vida y su entorno, recordando que la participación no figura en el listado de los derechos fundamentales consagrados por la Convención Internacional, la que, como es bien conocido, se sustenta en el paradigma de la protección.

Como documento de referencia básica habremos de utilizar el manual que elaborara la organización internacional Save the Children para que su personal ponga en marcha el enfoque de derechos del niño en la programación de sus actividades.

${ }^{1} K u h n$, T.S. (1971) La estructura de las revoluciones científicas, México, Fondo de Cultura Económica.

${ }^{2}$ Goleman, D. (1996) Emocional Intelligence, New Cork, Bantam Books. 
Comparación de ambos enfoques ${ }^{3}$

\begin{tabular}{|l|l|}
\hline \multicolumn{1}{|c|}{$\begin{array}{c}\text { Perspectiva de } \\
\text { necesidades }\end{array}$} & \multicolumn{1}{|c|}{$\begin{array}{c}\text { Perspectiva } \\
\text { de derechos }\end{array}$} \\
\hline Caridad privada. & $\begin{array}{l}\text { Responsabilidad pública, } \\
\text { política, moral legal, obliga- } \\
\text { ción y deber. }\end{array}$ \\
\hline Voluntario. & Obligatorio. \\
\hline Bienestar, limosnas, caridad. & $\begin{array}{l}\text { Derechos legales, demandas, } \\
\text { garantías, justicia, igualdad, } \\
\text { libertad. }\end{array}$ \\
\hline $\begin{array}{l}\text { Trata los síntomas. } \\
\text { Metas parciales (se inmuniza } \\
\text { al 80\% de los niños; se pre- } \\
\text { tende prestar servicio al } \\
\text { mayor número de personas). }\end{array}$ & $\begin{array}{l}\text { Trata las raíces y las causas. } \\
\text { nas tienen iguales derechos } \\
\text { (la inmunización al 80\% sig- } \\
\text { nifica que el derecho a la } \\
\text { inmunización no se ha cum- } \\
\text { plido). }\end{array}$ \\
\hline $\begin{array}{l}\text { Jerarquía de necesidades. } \\
\text { Algunas necesidades son más } \\
\text { importantes que otras (ali- } \\
\text { mento antes que educación). }\end{array}$ & $\begin{array}{l}\text { Los derechos no pueden divi- } \\
\text { dirse, son indivisibles e inter- } \\
\text { dependientes. }\end{array}$ \\
\hline $\begin{array}{l}\text { Las necesidades varín según } \\
\text { la situación, el individuo y el } \\
\text { entorno. }\end{array}$ & $\begin{array}{l}\text { Los derechos son universales } \\
\text { (los mismos en cualquier } \\
\text { lugar). }\end{array}$ \\
\hline $\begin{array}{l}\text { Empoto de necesidades). } \\
\text { chos). } \\
\text { Poseedores de derechos (tie- } \\
\text { nen poder de) exigir sus dere- } \\
\text { chos. }\end{array}$ \\
\hline
\end{tabular}

${ }^{3}$ Tomado de Save the Children, Programación de los derechos del niño. Cómo aplicar un enfoque de derechos del niño en la programación. Stockholm, Alianza Internacional Save the Children, 2002, p. 22. 


\begin{tabular}{|c|c|}
\hline $\begin{array}{c}\text { Perspectiva } \\
\text { de necesidades }\end{array}$ & $\begin{array}{l}\text { Perspectiva } \\
\text { de derechos }\end{array}$ \\
\hline $\begin{array}{l}\text { La determinación de las necesi- } \\
\text { dades es subjetiva. }\end{array}$ & $\begin{array}{l}\text { Los derechos se basan en } \\
\text { estándares internacionales. }\end{array}$ \\
\hline $\begin{array}{l}\text { Perspectiva a corto plazo, } \\
\text { cerrando brechas. }\end{array}$ & Perspectiva a largo plazo. \\
\hline Provisión de servicios. & $\begin{array}{l}\text { Mayor toma de conciencia por } \\
\text { todos los grupos (padres, niños, } \\
\text { tomadores de decisiones). }\end{array}$ \\
\hline $\begin{array}{l}\text { Proyectos específicos orienta- } \\
\text { dos a grupos específicos de } \\
\text { niños. }\end{array}$ & Enfoque integral. \\
\hline Los niños merecen ayuda. & $\begin{array}{l}\text { Los niños tienen derecho a } \\
\text { recibir ayuda. }\end{array}$ \\
\hline $\begin{array}{l}\text { Los gobiernos deben hacer } \\
\text { algo, pero nadie tiene obliga- } \\
\text { ciones definidas. }\end{array}$ & $\begin{array}{l}\text { Los gobiernos tienen obliga- } \\
\text { ciones morales y legales. }\end{array}$ \\
\hline $\begin{array}{l}\text { Los niños pueden participar con } \\
\text { el fin de mejorar la prestación } \\
\text { de servicios. }\end{array}$ & $\begin{array}{l}\text { Los niños son participantes } \\
\text { activos por derecho. }\end{array}$ \\
\hline $\begin{array}{l}\text { Debido a la escasez de recur- } \\
\text { sos, algunos niños pueden ser } \\
\text { excluidos. }\end{array}$ & $\begin{array}{l}\text { Existe una meta global a la cual } \\
\text { todo trabajo contribuye. }\end{array}$ \\
\hline $\begin{array}{l}\text { Cada trabajo tiene su propia } \\
\text { meta y no existe un propósito } \\
\text { global unificado. }\end{array}$ & $\begin{array}{l}\text { Todos los niños tienen el } \\
\text { mismo derecho a desarrollar su } \\
\text { potencial a plenitud. }\end{array}$ \\
\hline $\begin{array}{l}\text { Ciertos grupos tienen la espe- } \\
\text { cialización técnica para satisfa- } \\
\text { cer las necesidades de los } \\
\text { niños. }\end{array}$ & $\begin{array}{l}\text { Todos los adultos pueden des- } \\
\text { empeñar un papel para el logro } \\
\text { de los derechos del niño (y los } \\
\text { niños también). }\end{array}$ \\
\hline
\end{tabular}




\section{Análisis crítico de estas supuestas antinomias}

1. A diferencia del enfoque sustentado en el derecho, que invoca responsabilidad pública, política, legal y moral, además de comprometer determinadas obligaciones de carácter axiológico, el enfoque a partir de las necesidades sería un ejercicio de caridad privada, probablemente enraizado en el pietismo religioso y la "mala conciencia" de quienes sintiéndose favorecidos, realizan acciones caritativas de alcance limitado. A escala comunitaria, estas acciones se expresan mediante "actividades solidarias" vecinales en los estratos socioeconómicos C, D y E; o por las campañas y colectas caritativas de clubes de damas de los estratos A y B. A escala macrosocial y global, en los fracasados programas de lucha contra la pobreza elaborados por el Banco Mundial luego del "consenso" de Washington, en el plano económico; y en el llamado conservadurismo compasivo que domina la escena política norteamericana.

Pero ocurre que todo el andamiaje del derecho internacional y la estructura de los organismos multilaterales que podrían financiar las iniciativas encaminadas a dar sustento, por ejemplo, a los planes nacionales de acción por la niñez y la adolescencia, que resultan del carácter vinculante de la Convención Internacional de los Derechos del Niño (en adelante, $\mathrm{CDN}$ ), están condicionados a las decisiones del grupo de siete naciones occidentales económicamente mas poderosas (a las que se ha sumado, precariamente, Rusia) y al poder de veto que tienen cuatro naciones (de las cuales, tres integran el G8) en el Consejo de Seguridad de la Organización de las Naciones Unidas. En pocas palabras, las obligaciones políticas y morales que emanan de la CDN son asimétricas y no pueden configurar un eje axiológico coherente, a nivel internacional, del enfoque de derechos. En el plano regional latinoamericano y local, la legislación vigente es fiel reflejo de Estados y gobiernos que no logran articular formas de participación y decisión democráticas, con la consecuencia que sus normas y programas no trascienden lo formal declarativo o lo formal legislativo. Este panorama se torna más sombrío cuando se toman en consideración dispositivos legales de tipo represivo contra los niños y adolescentes, como lo fueran en un pasado reciente las leyes contra el terrorismo y el pandillaje pernicioso; y lo es en la actualidad la ley contra la mendicidad infantil, por citar el caso peruano.

Afirmar con tanta arrogancia que el enfoque de derechos garantiza que los estados y la sociedad civil, como ejecutores y vigilantes de 
las obligaciones que prescribe la CDN, van a comprometerse en sus responsabilidades y deberes frente a los niños, no pasa de ser una reificación más.

Lo que, de otro lado, no significa avalar el pietismo o la compasión como estilo de afronte al niño como sujeto cultural y actor de su propio desarrollo.

2. Siguiendo esa línea de razonamiento respecto al enfoque de derechos, el cuadro precedente establece, sin más, que tal enfoque es obligatorio, como si la desigualdad y la pobreza pudieran suprimirse por decreto. Descalificar indirectamente el voluntariado, como parece inferirse de la comparación establecida, no deja de ser un despropósito en países tan necesitados de la conjunción de esfuerzos como los nuestros. Por mencionar un ejemplo, de no ser por el compromiso post-convencional, en la formulación de Kohlberg ${ }^{4}$, del personal sanitario encargado de realizar la vacunación casa por casa, la eliminación al 100\% del virus salvaje de la Poliomielitis no hubiera sido posible, como tampoco serían posibles las coberturas en inmunizaciones del $80 \%$, que a los autores de ese cuadro no les parecen convincentes, por razones que analizaremos más adelante.

3. El tercer punto del cuadro es reiterativo del primero. Se invoca la superioridad de los derechos frente a las limosnas y la caridad, lo que parece plausible. Lo que no resulta claro es si la palabra bienestar, incluida en la columna del enfoque de las necesidades, se refiere al Estado de Bienestar (Welfare State) o a la sensación subjetiva de bienestar. En uno u otro caso, procurar el bienestar de los niños no tendría porqué ser un objetivo ajeno a sus necesidades o derechos. La definición mas convencional de salud alude precisamente a que no se trata de la mera carencia de síntomas, sino a esa sensación subjetiva de bienestar tan necesaria para que todos los seres humanos sintamos que la vida "vale la pena vivirla", aspiración de más del 50\% de la humanidad que vive en pobreza/exclusión.

$\mathrm{Si}$, por otro lado, cuestiona el estado de bienestar, cabría preguntarse si este es peor que el desmantelamiento de los programas socia-

\footnotetext{
${ }^{4}$ Kohlberg, L. (1971) From is to ought; en: T. Mischel (ed.) Cognitive Development and Epistemology, New York, Academic Press.
} 
les, como consecuencia de las políticas de ajuste financiero, el desempleo y la desvinculación que caracterizan a la teología del neoliberalismo.

Los otros enunciados no pueden ser más ilusorios: el enfoque de derechos garantizaría la justicia, la igualdad, la libertad. ¿Por qué no incluir la fraternidad y así completar los bellos propósitos de la Ilustración que, extrapolados a nuestras incipientes democracias en el siglo XIX, han producido el desencuentro del país formal con el país real en pleno siglo XXI?

4. El enunciado siguiente es tan abarcativo y holístico como el que le sucede. Según el mismo, el enfoque de derechos apunta a la solución de las raíces y las causas de los problemas por los cuales el niño necesita que se garanticen su supervivencia, desarrollo, protección y participación, si se restringe el conjunto de dispositivos de la CDN a esos cuatro aspectos (uno de los cuales, la participación, no aparece explícitamente como derecho en su texto ${ }^{5}$. Ahora bien, es posible imaginar que se están realizando evaluaciones periódicas de los informes que presentan los estados y los representantes de la sociedad civil de los países que cumplen con el mandato de la CDN y las observaciones del comité de Ginebra. Pero, ¿permite eso afirmar que se están cumpliendo las metas programáticas de los planes nacionales de acción? ¿Que las tasas de desnutrición o enfermedades infecto-contagiosas han disminuido en proporción tal que la supervivencia de los niños latinoamericanos está realmente garantizada por la eliminación de las causas subyacentes a esos dos procesos (la pobreza y la exclusión)?

¿Que las coberturas educativas y la calidad de la enseñanza aseguran posibilidades de desarrollo en igualdad de oportunidades para todos los niños?

¿Que los niños están protegidos de la violencia familiar, social, política o económica?

${ }^{5}$ Salvo en su artículo 31, en que lo restringe a actividades artísticas, culturales $y$ recreativas. 
¿Que participan auténticamente en la toma de decisiones en asuntos que les conciernen?

Sí, es verdad que el día a día de las necesidades urgentes puede relegar a segundo plano la planificación, diseño y monitoreo de programas de largo alcance, pero de ahí a decir que el enfoque de derechos ataca la causa de los problemas que sufren los niños, media la misma distorsión que llevó a los técnicos del Banco Mundial a obligar a los países a implementar programas de compensación de la pobreza frente a las consecuencias a los deshumanizados designios de su socio, el Fondo Monetario Internacional, al aplicar sus programas de ajuste fiscal, como lo demuestra palmariamente la experiencia argentina...

5. Las aspiraciones totalizadoras llevan a los totalitarismos y al desencanto. Señalar que la inmunización al $80 \%$ significa que la inmunización no se ha cumplido es un juego de palabras que no tiene sentido epidemiológico serio y que nuevamente nos remite a imágenes ideales carentes de sustento en la realidad. Su expresión más connotada en el sector salud, fue el énfasis que sobrevino a la conferencia de Alma Ata en torno a la Atención Primaria Integral y la posibilidad de procurar salud para todos el año $2000^{6}$. La imposibilidad de erradicar todas las enfermedades inmunoprevenibles o de modificar radicalmente los entornos de la pobreza condujo a programas de atención primaria selectiva, siendo los más destacados el AIEPI, EDA e IRA, para las patologías mas frecuentes como desnutrición e inmunizaciones, enfermedades diarreicas e infecciones respiratorias agudas, respectivamente, programas todos con reconocido éxito internacional. En cambio, programas más abarcativos, como el SMALP (Salud, Medio Ambiente y Lucha contra la Pobreza), tuvieron aplicabilidad limitada, no obstante contar con financiación internacional. Siendo verdad que ahora se prefieren abordajes comunitarios integrales por ciclo de vida, con énfasis preventivo-promocional y no solo por riesgos y daños, también sigue siendo cierto que quien mucho abarca poco aprieta.

\footnotetext{
${ }^{6}$ Lo que fue distorsionado al no tenerse en cuenta que no se aspiraba a que toda la población esté sana ese año, sino que tuviera los recursos de nivel primario suficientes para preservar o recuperar su salud.
} 
Algo similar se puede decir, y tomando nuevamente como ejemplo el caso peruano, respecto a la educación. En el Perú, con una inversión por debajo del promedio latinoamericano, se obtuvieron coberturas educativas de más del $90 \%$ en la escuela primaria en los ' 90 . Inspirados en las teorías de ajuste del gasto estatal y la precarización del empleo, esta expansión se obtuvo, básicamente, mediante la contracción de los salarios de los maestros. El resultado fue que las horas pedagógicas por año en la escuela pública, en los ámbitos rurales y urbano-marginados, llegaron a alcanzar menos del $50 \%$ de las dedicadas por la escuela privada. Consecuentemente, sucesivas evaluaciones de la calidad educativa pública a nivel internacional, han colocado al Perú como uno de los países con peores resultados a escala mundial.

6. La perspectiva de derechos establece que los derechos son indivisibles e interdependientes. No siendo experto en doctrina jurídica, no me atrevería a discutir la pertinencia operativa de tan rotunda afirmación. Pero sí se puede utilizar la teoría sistémica para comprender que todos los procesos que comprometen o facilitan el adecuado funcionamiento de las personas y las sociedades se retroalimentan. Consiguientemente, no es el enunciado jurídico de un derecho lo que hace factible su ejercicio, ya que, en el mejor de los casos, su formulación normativa podrá sustentar la viabilidad de un propósito. Ahora bien, y como veremos más adelante, el ejercicio de esos derechos está condicionado por variables que no son precisamente jurídicas y que en algunos casos involucran la moratoria del derecho (como el caso del trato diferencial que hace el Código de los Niños y Adolescentes peruano respecto al derecho de opinión de los mismos, sujeto al criterio de madurez, el que es recogido también en el preámbulo y el artículo 12 de la CDN) o la imposibilidad factual de ejercerlo (como en el caso de los derechos civiles, económicos y sociales de esos mismos niños y adolescentes).

Quiérase o no, la propia CDN consagra una gradualidad en el ejercicio de los derechos de los niños y adolescentes que rompe con la noción de indivisibilidad. Y si esto es cierto, el criterio de jerarquización de las necesidades no deviene necesariamente restrictivo, mas sí operativo. Maslow ${ }^{7}$ señala claramente que satisfacer las necesidades vitales básicas (alimento, sueño, abrigo) es un prerrequisito para alcanzar otros

${ }^{7}$ Maslow, A. El desarrollo de la personalidad, separata s.f. 
objetivos del desarrollo y en su esquema de necesidades y satisfactores, Max Neef y colaboradores ${ }^{8}$ aplican el mismo criterio de gradualidad cuando se refieren a los niños y adolescentes. Lo contrario sería violentar sus procesos de maduración en aras de justificar dos fenómenos estrechamente ligados a estos temas: la idealización y la ideologización del niño, como ente sobrenatural que no admite cortapisa alguna, cuando lo que se pretende, en realidad, es manipularlo y someterlo al imaginario de algunos adultos.

7. Otra afirmación tan rotunda como la anterior es que los derechos son universales (los mismos en cualquier lugar). Al respecto, ya Malinowski ${ }^{9}$ decía que:

"Es, empero, evidente que el conflicto infantil no puede ser el mismo en la lujosa "nursery” del burgués acaudalado que en la choza del aldeano o en la habitación única y promiscua del obrero pobre”.

Los derechos como enunciados de una convicción moral o una voluntad política pretenderán tener alcance universal, pero es evidente que la desigualdad en el goce de los derechos así proclamados es más bien la regla que la excepción en nuestros países.

Por lo demás, en un país pluriétnico y multicultural como el Perú (y nuestros hermanos andinos de Bolivia y Ecuador), el alcance universal de esos derechos está sujeto a variables exosistémicas aplastantes, las que, de no ser tomadas en cuenta, pondrían en riesgo la existencia misma de las culturas ajenas al mole occidental.

En este caso sí se puede concordar con el enfoque por necesidades, cuando sostiene que las necesidades varían según la situación, el individuo y el entorno.

Un ejemplo claro es el resultado de la aplicación de los planes de erradicación de las formas más penosas de trabajo infantil implementados por la OIT. Han transmitido la imagen de que todo trabajo infantil es perjudicial y no han logrado erradicar esas formas extremas de trabajo infantil que se caracterizan por la explotación del niño. Para ejemplo, baste citar el caso de las ladrilleras circundantes a Lima, en las que

\footnotetext{
${ }^{8}$ Max Neef, M. (1986) Historia, Economía y algunas invisibilidades; en: La economía descalza, Estocolmo, Buenos Aires, Montevideo, Norton.

${ }^{9}$ Malinowski, B. (1949) Estudios de Psicología Primitiva, Buenos Aires, Paidos.
} 
ciertamente trabajan los niños en condiciones de explotación. Al no haberse resuelto el problema de la pobreza extrema de las familias de esos niños, bajo diversos subterfugios siguen laborando en esas ladrilleras, no obstante un aparente éxito inicial del programa de erradicación allí promovido. Un efecto más perverso aún tuvo la erradicación del trabajo de las niñas en los lavaderos de oro del departamento de Madre de Dios. Al hacerse poco rentable su trabajo en los lavaderos, estas niñas no retornaron a sus lugares de origen (Cusco, principalmente), sino que permanecieron en los campamentos mineros, ahora dedicadas a la prostitución.

La aplicación generalizada de un dispositivo legal no garantiza, necesariamente, el cumplimiento de los principios que inspiraron a ese dispositivo.

8. El octavo punto del cuadro que comentamos parece ser el medular de toda la argumentación a favor de un enfoque de derechos. Se señala que la satisfacción de las necesidades es objeto de necesidades. No se entiende bien el fraseado de este enunciado pero es presumible que signifique que la satisfacción de las necesidades tiene como objetivo la satisfacción de las mismas en una escala reduccionista o constreñida a lo inmediato. La otra interpretación podría ser que la satisfacción es un objeto de las necesidades. Esto es una verdad de Perogrullo. La satisfacción es el objeto central del desarrollo ontológico saludable. Esta es un constructo que trasciende lo metapsicológico y se puede operativizar en indicadores válidos de desarrollo. Así lo entendió el Programa de Desarrollo de las Naciones Unidas cuando estableció los Índices de Desarrollo Humano, los que integran tres variables: la esperanza de vida al nacer, el logro educacional (alfabetización de adultos y la tasa bruta de matriculación primaria, secundaria y terciaria combinada) y el Producto Bruto Interno real per cápita (PPA en dólares). Por su parte, el Instituto Nacional de Estadística e Informática peruano intentó construir indicadores de desarrollo para la infancia que se sustentaban en el grado de satisfacción de determinadas necesidades. El problema que trabó este empeño derivó de la equivocada elección de algunos satisfactores (se escogió la posesión de un receptor de TV como indicador de la satisfacción de los niños y adolescentes, por ejemplo, sin tomar en cuenta los contenidos -generalmente estupidizantes en la señal abierta, que es la más accesible- que emitían las estaciones privadas de TV y dejando de 
lado algunas elaboraciones de Max Neef para construir satisfactores para la población infantil.

El enfoque de derechos parte de dos premisas finalísticas: el empoderamiento de las personas (sujetos de derecho) y la posesión real de los derechos, esto es, que las personas tienen el poder de exigir sus derechos. En definitiva, una sola visión ideal que se muerde la cola.

De acuerdo a estas premisas, y en concordancia con la Declaración Universal de Derechos Humanos, los derechos humanos y el desarrollo humano tienen una visión común y un propósito común: velar por la libertada, el bienestar y la dignidad de todos en todas partes. Esto significa velar por:

Libertad de la discriminación, ya sea en razón del género, la raza, el origen nacional o étnico o la religión.

Libertad de la necesidad ${ }^{10}$, para disfrutar de un nivel decente de vida. Libertad para desarrollarse y hacer realidad la potencialidad humana de cada uno.

Libertad del temor, de las amenazas contra la seguridad personal, de la tortura, de la detención arbitraria y otros actos violentos.

Libertad de la injusticia y de las violaciones del imperio de la ley.

Libertad para participar en la adopción de decisiones, de expresar las opiniones y formar asociaciones.

Libertad para tener un trabajo decente, sin explotación.

Se ha señalado anteriormente que los derechos civiles y jurídicos de los niños están condicionados por su madurez y también por su edad (art. 12 de la CDN), por lo que el ejercicio práctico de los mismos entra en la condición de moratoria.

Habría que añadir que, en general, los pobres y los excluidos no tienen goce de derechos económicos, sociales y culturales; y que el ejercicio de los derechos políticos se limita a la participación en actos eleccionarios viciados de origen por la inequidad en la información de los electores y la selección amarrada al poder económico de los postulantes a ser elegidos. En la práctica y como es de fácil constatación, existen ciudadanos de primera, de segunda y hasta de tercera. Los derechos no son ejerci-

\footnotetext{
${ }^{10}$ Resaltado en negritas por el autor.
} 
dos por todos y por igual. En algunos países desarrollados, la segmentación de los ciudadanos por su origen migratorio es una práctica respaldada por leyes específicas. En los nuestros, siempre formales y declarativos, todos somos iguales ante la ley, a despecho de las profundas desigualdades que hacen imposible el ejercicio de todos los derechos ciudadanos.

El último recurso de esta suerte de pie forzado consiste en sostener que es mejor que el enunciado de estos derechos marque la pauta de ciertas obligaciones que el estado, algún día, se verá forzado a cumplir. Una vez más, la constatación diaria de los acontecimientos nos ilustra cómo estos propósitos acaban constriñéndose a intenciones y las intenciones acaban convirtiéndose en buenos deseos, pero poco más. El empoderamiento comunitario, como práctica participativa de la sociedad civil, acaba manifestándose mediante asonadas políticas episódicas, que pueden tener éxitos impactantes como los ocurridos en Ecuador o Argentina, pero que, a la larga, no modifican las estructuras de poder y de políticas económicas preponderantes, como se aprecia en la experiencia reciente de esos mismos países.

Las libertades listadas al inicio de este acápite deben parecer una burla cruel a la mayoría de los pobladores latinoamericanos. Cada una de ellas está menoscabada o anulada en las formas más sutiles o groseras de que disponga el poder dominante. Baste resaltar la forma en que las políticas de desregulación laboral y la no viabilidad del compromiso social en los tratados de comercio vienen favoreciendo el trabajo precario, la amenaza diaria de despido, el desempleo y la pérdida de casi todos los derechos sociales que alcanzaron los trabajadores luego de siglos de luchas. Lo que trae como consecuencia la imposibilidad real de gozar de la libertad de la necesidad...ni siquiera para alcanzar un nivel de vida decente, sino lisa y llanamente sobrevivir.

Al final, lo único que perdura es la necesidad...y el imperativo de satisfacerla.

9. Pero es en este punto en el que se expresa con toda claridad el verdadero trasfondo etnocéntrico del enfoque de derechos. Cuando se afirma que este enfoque se basa en estándares internacionales ${ }^{11}$, en comparación con la subjetividad en la determinación de las necesidades.

11 Resaltado en negritas por el autor. 
Veamos cómo se justifica en el documento que nos sirve de referencia este supuesto apodíctico:

"Hay dos buenas razones por las cuales las instituciones adoptan programas con enfoque de derechos al elaborar sus programas (sic). Primero, porque creen que es moralmente correcto y, en segundo lugar porque piensan que ofrecen un conjunto de beneficios frente a los enfoques tradicionales. Estos beneficios incluyen:

* Proporcionar una meta a largo plazo, a la cual se orienta todo el trabajo y un conjunto de estándares para medir el progreso alcanzado.

* Una meta y estándares claramente establecidos dentro de un marco legal internacional, los que son compartidos por los gobiernos, los donantes y la sociedad civil.

* Identificar las responsabilidades de los gobiernos, de los donantes, del sector privado, de las comunidades y de los individuos, comprometiéndolos para la acción, así como maneras de hacerlos rendir cuentas.

* Incorporar dentro de un planeamiento integral, lo que se conoce como "buena práctica de desarrollo" (esto es, un enfoque sobre la participación, la equidad, la sostenibilidad, la no-discriminación, la erradicación de la pobreza y el trabajo multisectorial)" ${ }^{\prime 2}$.

Todo ello parece medianamente sensato, si no reparáramos en algunas cuestiones centrales que parecen ocultarse, deslizarse con medias palabras o distorsionarse sutilmente. Veamos algunas:

En el introito de la explicación reseñada, se sostiene textualmente que:

"Los gobiernos, los donantes, las agencias de la ONU, las compañias, las ONG y otras organizaciones de la sociedad civil tienden a hablar más sobre los derechos humanos y a contar con políticas a este respecto, aún cuando sus programas no reflejan todavía un cambio de enfoque. Un número importante de países donantes (por ejemplo Suecia, los Países Bajos, Canadá y el Reino Unido) y las agencias de la ONU han empezado a debatir respecto a cómo enfocar mejor su ayuda y asistencia para el desarrollo, con el fin de obtener un mayor impacto en el cumplimiento pleno de los derechos humanos".

${ }^{12}$ Save the Children, Programación de los Derechos del Niño...p. 23. 
Queda, pues, claramente establecido que el orden de prelación en este nuevo "consenso" acerca del enfoque de derechos, no pasa primero por los gobiernos (mal que bien, representantes legítimos de las naciones en la comunidad internacional y supuestos garantes del derecho internacional), sino por los donantes, y que son tres países emblemáticos de la Alianza Save the Children (Suecia, Canadá y Reino Unido), sin mencionar la impronta de su contraparte norteamericana ${ }^{13}$, los que han decidido que para financiar determinados programas es necesario que se sometan al marco lógico de su programación, desde la perspectiva de los funcionarios técnicos que contratan localmente para garantizar que las cosas se hagan de acuerdo a las "buenas prácticas de desarrollo".

¿Dónde quedan la Investigación-Acción Participativa y el empoderamiento de las comunidades locales? ¿Por dónde asoma la participación y el poder decisorio de las opiniones de los niños?

El poder vinculante de la CDN obliga a los países, es cierto, a presentar planes integrales de acción por los niños. Lo que se oculta es que esos planes están desfinanciados desde su origen, que no existe coordinación intersectorial en su aplicación y que no responden al criterio proteccionista de la propia Convención, sino a las exigencias economicistas en boga. Por ejemplo, el análisis de la aplicación de los programas dirigidos a la infancia en el Perú en la década del ' 90 reveló que la inversión en sus cuatro componentes principales (salud, educación, nutrición y vivienda) fue pro-cíclica y ni siquiera alcanzó las coberturas de un plan de emergencia ante las sucesivas crisis económicas que sufrió el país (el shock económico por las políticas de ajuste del FMI en 1990 y las crisis internacionales desatadas por la ineficiencia de ese mismo organismo internacional en los años siguientes). Los gastos registrados en esas épocas de crisis revelaron cifras menores en el área social en esos años, lo que significa que ni siquiera cubrieron metas "asistencialistas", mucho menos una política de inversión de acuerdo a la "buena práctica de desarrollo"14.

Se desliza la idea de otro supuesto: los organismos internacionales y los gobiernos, gracias al establecimiento de "estándares internacio-

\footnotetext{
${ }^{13}$ Save the Children USA es la que maneja los presupuestos más abultados de la Alianza.

${ }^{14}$ Vásquez, E. y Mendizábal, E. (2002) ¿Los niños...primero? El gasto público social focalizado en niños y niñas en el Per'r 1990-2000, Lima, Centro de Investigación de la Universidad del Pacífico/Save the Children Suecia.
} 
nales" estarían sujetos a normas de transparencia y accountability impecables. Lo cierto es que la corrupción de los gobiernos latinoamericanos ha aumentado considerablemente en los últimos años, siendo los casos argentino y peruano por demás paradigmáticos. Tampoco se revelan los montos de las ayudas que realmente llegan a los beneficiarios, y ello por la sencilla razón que muchos de los organismos multilaterales destinan más dinero a gastos corrientes (planillas y gastos administrativos) que a los niños. Se calcula que el $80 \%$ del presupuesto de UNICEF se dispendia de esa forma y un informe oficial del propio IPEC (Programa de Erradicación de las peores formas de Trabajo Infantil), preparado por el gobierno español que financia ese programa en toda Sudamérica, con excepción de Brasil, indica que más del $50 \%$ de su inversión fueron consumidos por el overhead de OIT (Organización Internacional del Trabajo, organismo que actúa como paraguas de este programa) y los gastos corrientes, entre los que destacan los pagos por pasajes y viáticos de los expertos internacionales.

Los estándares internacionales no son establecidos, pues, por la mano divina, sino por la mano invisible del mercado y el liberalismo clásico, ahora remozado con el moquete de neo-liberalismo. Se basan en nociones de rentabilidad gerencial y no de solidaridad y contienen toda la subjetividad que corresponde a todo hecho social, esto es, sus percepciones, distorsiones e intenciones.

Decir entonces que la determinación de las necesidades es subjetiva es mirar la paja en ojo ajeno. Es probable que la priorización de las necesidades sufra de los avatares de subjetividad anteriormente señalados para el enfoque de derechos, pero tienen un respaldo metodológico elaborado y probado en el tercer mundo, por el grupo de CEPAUR que encabeza el premio Nobel alternativo Manfred Max Neef.

Este grupo ha elaborado una plantilla de necesidades y satisfactores (ver anexo 2) que comprende cuatro necesidades según categorías existenciales (ser, tener, hacer, estar) y nueve categorías axiológicas (subsistencia, protección, afecto, entendimiento, participación, ocio, creación, identidad y libertad) ${ }^{15}$, perfectamente compatible con las necesidades de desarrollo y maduración de los niños. Los satisfactores pro-

${ }^{15}$ Para un análisis detallado de esta matriz y su significado para la infancia, consultar el ensayo del autor El abordaje de las necesidades de los niños excluidos, Lima, UNMSM, en prensa. 
puestos, de otro lado, no parten de la perentoriedad de la rentabilidad económica o de la lógica de las "buenas prácticas de desarrollo" de la gerencia estratégica, que al final no son otra cosa que el conservadurismo compasivo ya apuntado, sino de la aspiración de todo ser humano a autorrealizarse, diseñándose ingeniosos sistemas de producción a escala humana y trueque que apuntan a la revaloración del trabajo en condiciones exentas de alienación.

10. Una crítica generalizada al enfoque de necesidades por su visión de corto plazo, parecería válida si no se tomara en cuenta la estrategia general de una economía con rostro humano que implica el planteamiento de Max Neef y colaboradores.

Nuevamente, asignar al enfoque de derechos la exclusividad de la perspectiva a largo plazo es la reafirmación de la superioridad del primer mundo en la búsqueda de soluciones para los problemas del tercer mundo, lo que ha probado ser inexacto si se sigue el relato de Stiglitz ${ }^{16}$ sobre sus experiencias con el Banco Mundial y el FMI. De acuerdo a las mismas, este último organismo multilateral fue incapaz de predecir una sola de las crisis económicas internacionales de los ' 90 y sus recetas para resolverlas, cuando ya se habían presentado, fueron generalmente contraproducentes, con el resultado esperado de que los perdedores fueran siempre los más pobres. Afirmar entonces que la perspectiva de derechos basada en la "buena práctica de desarrollo" tiene perspectiva de largo plazo, no pasa de ser un buen deseo, como lo analizaremos en el acápite 14 .

11. En este punto, la perspectiva de derechos vendría a ser la concreción del advocacy en su doble acepción de defensoría o abogacía social y concepción generadora de empoderamiento comunitario. Al haber mayor conciencia ¿de qué? por parte de los grupos comprometidos (padres, niños, tomadores de decisiones), estos grupos estarían en posición de presionar a los gobiernos para que cumplan sus obligaciones frente a los niños. Lo cierto es que los niños no tienen peso político y los políticos utilizan a los grupos defensores de sus derechos como plataforma electoral declarativa. Los tomadores de decisiones, por su parte, son funcionarios designados por el poder de turno, con una alta tasa de rota-

${ }^{16}$ Stiglitz, E. El malestar en la globalización, Buenos Aires, Taurus. 
ción en el cargo y con escasas posibilidades de planificar a largo plazo; o son miembros de ONG's que dependen de donantes foráneos, razón por la cual -ambos tipos de "tomadores de decisiones" -se esmeran en emprender acciones cortoplacistas que les permitan mostrar "resultados" a sus mentores o a los organismos internacionales que financian esas acciones. Como ha sido señalado por otros autores, gran parte de la folletería instruccional que producen las organizaciones públicas y privadas que se ocupan de los niños, no está dedicada a los niños o sus padres, sino a impresionar favorablemente a los organismos que financian a esos operadores locales. El empoderamiento comunitario deviene entonces en un ejercicio de ficciones que se retroalimentan.

Llama la atención la connotación aparentemente negativa, por ser una práctica adscrita al enfoque de necesidades, que se asigna a la provisión de servicios en este punto. ¿Es que no es correcto brindar un servicio a quien lo necesita?

12. En este punto se destaca que el enfoque de derechos es integral, en tanto que el enfoque por necesidades está direccionado a proyectos específicos orientados a grupos específicos de niños.

Aún aceptando que los derechos sean indivisibles, interdependientes y universales, no se concibe cómo pudieran ser operacionalizados in totto dentro de una programación entendida como planeamiento, implementación, monitoreo y manejo de un conjunto de actividades orientadas hacia una meta definida. Esto es, que toda programación requiere de objetivos, metas y resultados esperados, con indicadores válidos de monitoreo y responsables claramente identificados, para que pueda ser aceptada dentro de la lógica establecida como premisa. Además, la programación de los derechos del niño en la práctica comprende un ciclo de programación con cuatro etapas básicas, a saber:
Análisis situacional.
Establecimiento de prioridades
Estrategias de implementación.
Monitoreo y evaluación.

Los conceptos anteriormente vertidos son un resumen del documento de referencia publicado por Save the Children como un manual para la implementación del enfoque de derechos en la programación de los derechos del niño. El énfasis (en negritas) es del autor. Y lo es para 86 
destacar que los criterios básicos así enunciados tienen en cuenta la diversidad de contextos en que se aplica esta programación, que las actividades a realizar son múltiples y que es necesario priorizar las intervenciones. En definitiva, aplicar los criterios del enfoque a partir de las necesidades que se cuestiona en los puntos 6,7 y 12 (el presente), cuando menos. De modo tal que no se echa de ver la falla atribuida al enfoque por necesidades, cuando se destaca que privilegia proyectos específicos, como si la especificidad de los proyectos atentara contra la integralidad de un enfoque, cualquiera que este sea. En tanto exista una base filosófica coherente y políticas definidas en el marco de metas evaluables, no tendría porqué desintegrarse la aplicación de cualquiera de los enfoques citados.

13. En este acápite se establece que los niños tienen derecho a recibir ayuda y que no es solo que la merezcan.

Totalmente de acuerdo. En su primera acepción, el verbo merecer implica hacerse uno digno de premio o castigo $^{17}$, en tanto que la cuarta acepción del mismo habla de hacer, méritos, buenas obras, ser digno de premio.

En ambos casos la ayuda así merecida devendría un reconocimiento ex post-facto y no un acto de solidaridad independiente de los méritos o deméritos del niño. Si la perspectiva de las necesidades aplicara ese criterio estaría regresionando a la doctrina del menor en situación irregular y estaría dejando de lado el principio fundamental de la CDN, cual es la necesidad de los niños de recibir protección. Esta protección debe ser irrestricta y no condicionada al comportamiento del niño, ya que su educabilidad, en principio, es también irrestricta.

14. Los gobiernos tienen obligaciones morales y legales, reza el título de este acápite, de acuerdo a la perspectiva de derechos. El cumplimiento de estos principios aseguraría la consecución de metas globales y a largo plazo.

La experiencia latinoamericana parece desdecir tan bien intencionado propósito. Lo cierto es que los gobiernos, a pesar de sus obligaciones para con el comité de Ginebra que vigila el cumplimiento de

\footnotetext{
${ }^{17}$ Real Academia Española, Diccionario de la lengua española, Real Academia Española de la Lengua, Madrid, 1992 (XXI edición).
} 
los planes nacionales de acción y establece metas definidas para el avance de la CDN, actúan siguiendo el enunciado atribuido malintencionadamente al enfoque de las necesidades. ¿Qué responsabilidad pueden tener las organizaciones que adscriben a esta perspectiva en el incumplimiento de los gobiernos?

Como ya se ha señalado, los gobiernos cumplen la obligación formal de presentar planes nacionales de acción, pero estos no tienen un cronograma de acción (en el caso peruano, se presentan un año después de su supuesta iniciación), no tienen asignaciones presupuestarias aseguradas y no hay mecanismos de evaluación establecidos (indicadores válidos de monitoreo, asignación de responsabilidades efectivamente concertada). Como es también conocido, los gobiernos latinoamericanos tienen por dogma el puntual pago de la deuda externa y la consecución de metas fiscales que satisfagan al FMI. Todo lo demás es secundario. Por tanto, el cumplimiento de sus obligaciones morales y legales es otra de tantas declaraciones líricas; y el logro de metas a largo plazo un enunciado librado al azar.

Si los gobiernos cumplieran, cuando menos, su rol normativo dentro del aparato del estado y su rol coordinador en la sociedad civil, sí se podría hablar de obligaciones definidas, viables y factibles. Pero ante la crisis de gobernabilidad que enfrentan muchos de ellos, el plantear expectativas tan altas acerca de su desempeño solo puede acarrear más frustración.

15. Los niños pueden participar con el fin de mejorar la prestación de servicios, reza el dictum para el enfoque por necesidades; en tanto que el enfoque por derechos, siempre cualitativamente superior en la presunción de los autores del cuadro que comentamos, son participantes activos por derecho.

El tema de la participación infantil ha dado lugar a la formulación de diversas concepciones teóricas y aplicaciones prácticas, que van desde su minusvaloración, expresada en la utilización funcional de los niños en labores de limpieza pública en la comunidad; hasta las posturas de quienes los ven como protagonistas sociales con ciudadanía plena y una suerte de superioridad inmanente en sus interacciones con los otros componentes de su entorno, en tanto que reserva ideológica de cara al futuro.

Naturalmente, estas posturas tan disímiles parten de diferentes concepciones de la infancia, ya no como tiempo de maduración y desa88 
rrollo, sino como producto cultural. En general, estas concepciones consideran al niño de la manera siguiente:

Niño/a como propiedad familiar/comunitaria.

Niño/a como futuro potencial.

Niño/a como figura decorativa/consumidor.

Niño/a como sujeto de derechos/necesitado de protección.

Niño/a como actor social.

Por otra parte y de acuerdo a Ángel Espinar ${ }^{18}$, la revisión bibliográfica sobre el tema de la participación infantil tropieza con la constatación de que los enfoques teóricos acerca de la misma no hacen explícito, a nivel conceptual, qué se entiende por participación. Este galimatías epistemológico da por resultado una confusión de paradigmas de los que es preciso hacer algunas aclaraciones, para no caer en la tautología.

El mismo autor cita a Cussiánovich y Márquez (2001), quienes señalan cinco tendencias que dan cuenta de la forma de elaborar los discursos sobre la participación de los niños en los diferentes espacios de la vida social:

I. La representada por la $\mathrm{CDN}$, en que no se explicita la participación en sentido extenso, pero contiene artículos relacionados con la no discriminación $\left(2^{\circ}\right)$, el interés superior del niño $\left(3^{\circ}\right)$, separación de los padres $\left(9^{\circ}\right)$, reunificación familiar $\left(10^{\circ}\right)$, el respeto por las opiniones del niño $\left(12^{\circ}\right)$, libertad de expresión $\left(13^{\circ}\right)$, libertad de pensamiento, conciencia y religión $\left(14^{\circ}\right)$, libertad de asociación $\left(15^{\circ}\right)$, acceso del niño a la información y papel de los medios de comunicación masiva $\left(17^{\circ}\right)$, niños privados de su entorno familiar $\left(20^{\circ}\right)$, adopción $\left(21^{\circ}\right)$, los casos de los niños con impedimentos físicos o mentales $\left(23^{\circ}\right)$ derecho a la educación $\left(28^{\circ}\right)$, derecho al tiempo libre, al juego y a la participación en actividades culturales y artísticas $\left(31^{\mathrm{o} 19}\right)$, que bien podrían sustentar formas de participación en tanto precursoras de decisiones, de no ser porque en el

\footnotetext{
${ }^{18}$ Espinar, A.(2003) Estudio para la elaboración de Indicadores e Instrumentos para analizar el componente de Participación de Niños y Niñas en proyectos sociales (SCS S046/02). El ejercicio del poder compartido, Lima, Escuela para el Desarrollo (Documento).

${ }^{19}$ ¿Será la única forma de participación del niño de acuerdo a la CDN?
} 
acápite 1 del artículo 12 se señala en forma precisa que el niño tendrá derecho a formarse su opinión, pero... teniéndose debidamente en cuenta las opiniones del niño, en función de la edad y madurez del niño, de lo que puede colegirse, como lo hace Save the Children (2001) que "los niños no deben verse obligados a adoptar una postura en asuntos en los que no tienen la posibilidad de ver las consecuencias". de ciudadanía.

II. La definición de Roger Hart, que está ligada a la condición

La figura de la "escalera de participación" de Hart, que va desde el tokenismo hasta la ciudadanía, muestra el proceso de avance de los niños desde la superación de roles predefinidos hasta llegar a una participación efectiva en las decisiones y finalmente compartir estas con los adultos.

Los planteamientos de Hart han venido siendo utilizados por ONGs que promueven la participación ciudadana y el efectivo ejercicio de derechos por la infancia. Como el mismo autor señala "la escalera de la participación sirve para designar el principio de una tipología para la reflexión sobre la participación de los niños en los proyectos". Además, constituye un medio por el que se construye democracia.

III. Según Peter Crowley, "la participación es un principio director clave, un derecho "facilitador", es decir, que su cumplimiento contribuye a asegurar el cumplimiento de todos los demás derechos. No es solamente un medio para lograr un fin, ni tampoco simplemente un "proceso"; es un derecho civil y político básico para todos los niños y, por tanto, es también un fin en sí mismo".

De acuerdo a este autor, el derecho a la participación debe darse en "todos los asuntos" que sean de particular interés para el niño y que puedan afectar su vida en los diferentes ámbitos en que está inserto, y no únicamente en las cuestiones tratadas explícitamente por la CDN. Esta concepción es defendida por UNICEF.

IV. De acuerdo a García y Mico, quienes han acuñado la noción de preciudadanía para los niños, estos son ciudadanos potenciales por las razones siguientes:

a. La existencia de un tiempo previo para la habilitación de los derechos cívicos y políticos (justificación política). 
b. Habría una socialización política deficiente en los niños, lo que no prepara a los niños para la democracia (justificación psicológicosocial).

c. Carencia de políticas públicas que reconozcan en los niños la calidad de ciudadanos sociales y sujetos de derechos socioeconómicos (justificación social).

d. La condición potencial del niño para adquirir virtudes éticas (justificación filosófica).

e. El carácter evolutivo de la formación moral del niño (justificación moral).

f. El tránsito de la heteronimia a la autonomía personal (justificación jurídica).

V. La definición de participación como protagonismo integral, fruto de la experiencia de quienes la propugnan con niños trabajadores y niños de la calle (o en la calle), y el análisis de la marginalidad en que viven estos. De acuerdo a este enfoque teórico se propone una perspectiva ideológica, educativa y ético-política de la promoción del protagonismo integral como práctica y estrategia metodológica. Uno de sus más activos propulsores, Cussiánovich (2002) sostiene que "el protagonismo permite retomar la condición de sujeto y actor del niño, de su derecho a la opinión, a tener voz, a participar en todo aquello que le concierne”.

Esta concepción de la participación contiene algunas premisas teóricas como son:

La participación es un derecho, de un fin instrumental para la consecución de otros derechos.

Es el ejercicio concreto de actoría social y de construcción de identidad. Es un principio, una práctica y un proceso que apunta no solo a la concientización del individuo sino a la construcción de actores sociales.

Está vinculado al ejercicio de la ciudadanía y el ejercicio del poder.

Tres objeciones pueden ser adelantadas respecto a esta postura. Las dos primeras han sido planteadas por el autor en un ensayo de próxima publicación y se refieren al riesgo de idealizar (específicamente al niño trabajador, por su condición de tal) e ideologizar al niño (en una suerte de manipulación intelectual propia de toda ideología). La otra está delimitada por la imposibilidad de definir cabalmente qué es una personalidad protagónica, en tanto que la personalidad del niño es una personalidad en formación. 
Volviendo a las antinomias que plantean las definiciones de participación a partir de los dos enfoques analizados, cabría decir que, ciertamente, no es atinado confinar al niño a tareas de servicio menores o de baja policía. Pero también es demasiado pretencioso sostener que todos los niños son participantes activos por derecho. ¿Participantes en qué?

Esto nos lleva a la consideración de los ámbitos en que participan los niños: grosso modo, se pueden diferenciar cuatro ámbitos formales y otro inmanente a su condición de niños. Los formales son la familia, la escuela, la organización y la comunidad. El inmanente es el juego. Una adecuada delimitación de estos ámbitos nos permitirá evaluar cuán auténtica y efectiva resulta la participación de los niños, y no declaraciones principistas de carácter totalizante que no añaden elemento alguno para operativizar el ejercicio de un derecho, si lo asumimos como tal.

Por ello es que se han operacionalizado indicadores de participación infantil ${ }^{20}$ que permiten monitorear la calidad de esa participación. Estos indicadores abarcan las esferas de la opinión de los niños, los mecanismos que se adoptan para la toma de decisiones y las acciones que emanan de las mismas. Son como sigue:

\begin{tabular}{|l|l|}
\hline \multicolumn{1}{|c|}{ Indicadores de proceso } & \multicolumn{1}{|c|}{ Indicadores de resultado } \\
\hline $\begin{array}{l}\text { La opinión }{ }^{21} \text { de los niños como } \\
\text { expresión de su satisfacción o }\end{array}$ & $\begin{array}{l}\text { La opinión de los niños es pro- } \\
\text { movida a través de espacios de } \\
\text { diálogo con otros. }\end{array}$ \\
insatisfacción. & La opinión de los niños es entre- \\
La opinión informada (sufi- \\
ciente y oportuna de los niños toman decisiones. \\
sobre asuntos que afectan sus & La opinión de los niños llega de \\
vidas. & modo completo al espacio de \\
La opinión reflexionada de los & toma de decisiones. \\
niños sobre asuntos que afec- & La opinión de los niños es toma- \\
tan sus vidas. & da en cuenta por los que toman \\
& decisiones. \\
\hline
\end{tabular}

${ }^{20}$ Espinar, A. Marco conceptual para comprender la participación de niños, niñas y adolescentes, Lima, Save the Children, 2003, Documento de trabajo. ${ }^{21}$ Opinión= manifestación del derecho de los niños a expresar su punto de vista de forma personal o grupal en determinados asuntos sobre los que tienen información y que esperan sea tomada en cuenta en los procesos de toma de decisiones que afectan sus vidas. 


\begin{tabular}{|c|c|}
\hline Indicadores de proceso & Indicadores de resultado \\
\hline $\begin{array}{l}\text { La opinión de los niños como } \\
\text { expresión de reconocimiento } \\
\text { personal o grupal. } \\
\text { La opinión de los niños refleja } \\
\text { la conciencia del derecho a opi- } \\
\text { nar. } \\
\text { Los niños cuentan con una } \\
\text { diversidad de opciones para } \\
\text { elegir. } \\
\text { Los niños son consultados y se } \\
\text { toma en cuenta sus opiniones. } \\
\text { Los niños eligen los procedi- } \\
\text { mientos para tomar decisiones. } \\
\text { Los niños eligen sus represen- } \\
\text { tantes ante los espacios de opi- } \\
\text { nión. } \\
\text { Los niños se reconocen en las } \\
\text { decisiones tomadas. } \\
\text { Los niños se responsabilizan } \\
\text { de sus propias decisiones. } \\
\text { La acción refleja el modo de } \\
\text { pensar y sentir de los niños. } \\
\text { La acción es producto de una } \\
\text { decisión personal y colectiva } \\
\text { de los niños. } \\
\text { La acción busca subsanar un } \\
\text { derecho afectado. } \\
\text { La acción refleja el sentido de } \\
\text { pertenencia al grupo u organi- } \\
\text { zación. }\end{array}$ & $\begin{array}{l}\text { Los niños cuentan con espacios } \\
\text { y mecanismos de toma de deci- } \\
\text { siones. } \\
\text { Los niños toman decisiones } \\
\text { directamente sobre los asuntos } \\
\text { que afectan sus vidas. } \\
\text { Los niños toman indirectamen- } \\
\text { te decisiones sobre asuntos que } \\
\text { afectan sus vidas. } \\
\text { Los asuntos sobre los que } \\
\text { toman decisiones favorecen el } \\
\text { interés superior del niño. } \\
\text { La acción refleja los asuntos de } \\
\text { interés de los niños. } \\
\text { La acción refleja la participa- } \\
\text { ción de los niños en asuntos } \\
\text { públicos. } \\
\text { La acción de los niños tiene un } \\
\text { carácter político definido2. }\end{array}$ \\
\hline
\end{tabular}

${ }^{22}$ Riesgo de ideologización y manipulación. 
Tomado en cuenta los ámbitos de participación y los indicadores de proceso y resultado señalados, se puede concluir en una definición de la participación infantil que esté atenta a sus necesidades (sin reducirlas) y a sus derechos (sin hacerlos objeto de grandilocuencia vacua). Esta podría ser:

"El ejercicio del poder que tienen los niños y las niñas para hacer que sus opiniones sean tomadas en cuenta seriamente y para asumir responsablemente decisiones, de acuerdo a su grado de madurez y desarrollo, en asuntos que afectan sus vidas y las de su comunidad".

16. En este acápite se vuelve a hacer otra afirmación candorosa cuando se trata de caricaturizar el enfoque por necesidades. Decir que "debido a la escasez de recursos algunos niños pueden ser excluidos" es una perogrullada que no merece discusión. Pero dar a entender que gracias al enfoque de derechos "existe una meta global a la cual todo trabajo contribuye", como si establecer metas globales fuera una manera de garantizar que niño alguno no quedara excluido, es tan ilusorio como en su momento lo fuera alcanzar la salud para todos el año 2000, el $100 \%$ de coberturas en todas las inmunizaciones o, en el caso patético de la dictadura que llenó de sombras al Perú en la última década del siglo pasado, emitir spots televisivos en los que se afirmaba que la meta de ese gobierno era hacer de la educación pública peruana la mejor de América Latina. Los resultados de sucesivas evaluaciones internacionales demostraron que era la peor.

La exclusión, como la pobreza, no se soluciona por decreto. El ejercicio de los derechos civiles, políticos, económicos, sociales y culturales es una aspiración democrática que no siempre alcanza a la totalidad de la población, sea esta adulta o infantil. Es más, los estudios sobre pobreza realizados en el Perú revelan que, proporcionalmente, los niños tienen un volumen porcentual ( 60 a $62 \%$ del total) mayor que el porcentaje total de pobres en el país (54\%).

Respecto a la exclusión, el estudio de Sinesio López ${ }^{23}$ no hace otra cosa que confirmar que, en el Perú, existen ciudadanos plenos en lo civil y lo político, pero que el goce de derechos económicos, sociales y

${ }^{23}$ López, S. (1997) Ciudadanos reales e imaginarios. Concepciones, desarrollo y mapas de la ciudadanía en el Perú, Lima, IDS. 
culturales está reservado a una minoría, siendo, más bien, la discriminación por estos motivos el eje central de los estilos de convivencia en este país.

Insisto. Es importante que existan metas globales que integren sistémicamente el trabajo en pro de los niños, pero la sola existencia de las mismas no garantiza, como se ha demostrado en acápites anteriores, la inclusión automática de los niños en el tejido de la nación. Por el contrario, las condiciones de pobreza y desigualdad en América Latina tienden a agudizar las condiciones de exclusión en que viven la mayoría de los niños de la región y generan sentimientos generalizados de desesperanza aprendida que los hace vulnerables a introyectar como propia la violencia del agresor (violencia política, violencia social, violencia económica, violencia cultural, violencia familiar, maltrato infantil).

17. En este acápite, la supuesta antinomia aparece descalibrada. Se compara en la columna correspondiente al enfoque por necesidades la carencia de metas globales (enunciado contrapuesto al asignado al enfoque de derechos en el acápite anterior) con el derecho de todos los niños a desarrollar su potencial a plenitud, supuesto que, a mi modo de ver, ninguno de los enfoques pone en tela de juicio.

Si de lo que se trata es resaltar la necesidad de un enfoque sistémico para el abordaje tanto de las necesidades cuanto de los derechos de los niños, igualmente vigente es esa noción en ambos casos. Lo que parece preocupante es que se asigne al enfoque de derechos una posición tan declarativamente lírica si se toman en cuenta las condiciones estructurantes de desigualdad entre los niños. ¿Es plausible pensar que las oportunidades de escolaridad y estudios superiores, trabajo digno y servicios de salud de calidad puedan ser iguales en un mundo signado por la desigualdad y la exclusión?

Si la contrapropuesta a partir del enfoque de derechos es que los planes nacionales de acción constituyen la expresión de un propósito global unificado, tendremos que referirnos, una vez más, a la falta de coordinación intersectorial en el ámbito de lo público y a la superposición de actividades de ONGs, que dejando de lado esa ideal visión y misión integrales, se vuelcan rápidamente al tema de moda con la sola finalidad de obtener la financiación externa que garantice su supervivencia, duplicando esfuerzos y -a veces- compitiendo entre ellas para copar esas fuentes de financiación, como es fácil observar en las organizacio- 
nes que se dedican al tema del uso y abuso de drogas adictivas entre los niños y adolescentes.

18. El último acápite sería digno de una interpretación psicoanalítica si se asumiera a la ligera su hermenéutica (cosa que algunos psicoanalistas suelen hacer sin empacho alguno en algunos medios de comunicación). Decir que "Todos los adultos pueden desempeñar un papel para el logro de los derechos del niño (y los niños también)" ${ }^{24}$, a partir de un enfoque de derechos, es -acto fallido mediante- aceptar el rol subsidiario del niño, la carencia de contenido en la noción del mismo como sujeto de derechos y la explícita negación de su participación en el logro de los mismos mediante el poder para tomar decisiones relevantes en su propia vida y los contextos que le toque vivir.

Con todo lo restrictiva que pueda parecer la caracterización atribuida al enfoque por necesidades ("Ciertos grupos tienen la especialización técnica para satisfacer las necesidades de los niños”), desde un punto de vista operativo, tal declaración suena más sincera. Tiene, ciertamente, ingredientes de asimetría y asistencialismo insalvables, pero -cuando menos- sigue una línea coherente desde su perspectiva: los adultos saben qué hacer para resolver los problemas de los niños.

\section{¿Lo saben realmente?}

La respuesta es un no rotundo.

Los adultos presumen que saben qué es lo que necesitan los niños y habitualmente los utilizan en forma operativa para los fines de satisfacción de sus propias necesidades narcisistas, de figuración social o política, por el manejo del relativo poder que les confiere su sumisión o por otras urgencias, a veces auténticamente pietistas... a veces inconfesables.

Los adultos son mediadores calificados para el desarrollo y maduración de los niños, en tanto y cuanto se ciñan a un estricto cumplimiento de las necesidades y los derechos de los propios niños. De no ser así, estarían descendiendo aceleradamente por la escalera de Hart hacia formas de manipulación que no han aportado mayor cosa a las legiones de niños desprotegidos y más bien abusados de esta inmensa aldea global en que se ha convertido el mundo.

\footnotetext{
${ }^{24}$ Mi énfasis.
} 